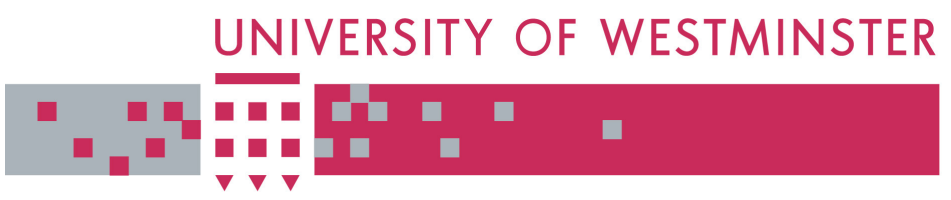

WestminsterResearch

http://www.wmin.ac.uk/westminsterresearch

\title{
Intelligent reconfiguration of large mobile networks using complex organic distributed architecture.
}

\author{
Tereska Karran \\ George Justo \\ Kambiz Madani
}

Cavendish School of Computer Science

Copyright (C) [2001] IEEE. Reprinted 2001 IEEE 52nd Vehicular Technology Conference (VTC 2001 - Spring).

This material is posted here with permission of the IEEE. Such permission of the IEEE does not in any way imply IEEE endorsement of any of the University of Westminster's products or services. Internal or personal use of this material is permitted. However, permission to reprint/republish this material for advertising or promotional purposes or for creating new collective works for resale or redistribution must be obtained from the IEEE by writing to pubs-permissions@ieee.org. By choosing to view this document, you agree to all provisions of the copyright laws protecting it.

The WestminsterResearch online digital archive at the University of Westminster aims to make the research output of the University available to a wider audience. Copyright and Moral Rights remain with the authors and/or copyright owners. Users are permitted to download and/or print one copy for non-commercial private study or research. Further distribution and any use of material from within this archive for profit-making enterprises or for commercial gain is strictly forbidden.

Whilst further distribution of specific materials from within this archive is forbidden, you may freely distribute the URL of WestminsterResearch.

(http://www.wmin.ac.uk/westminsterresearch).

In case of abuse or copyright appearing without permission e-mail wattsn@wmin.ac.uk. 


\title{
Intelligent Reconfiguration of Large Mobile Networks using Complex Organic Distributed Architecture.
}

\author{
Tereska Karran, George Justo, Kambiz Madani \\ University of Westminster, 115 New Cavendish Street, London W1W 6UW \\ Karrant $@$ wmin.ac.uk, Justog@wmin.ac.uk, Madani@emsa.wmin.ac.uk
}

\begin{abstract}
This paper presents a possible solution to the intelligent evolution of mobile systems using a Complex Organic Distributed Architecture (CODA), which supports intelligent reconfiguration of all system components. A key feature of this architecture is the deployment of multiple warehouses. The warehouses store data in a variety of ways depending on the type of intelligence required. On Line Analytical Processing (OLAP) software is used to monitor and control data in the system. An effective system of filters and wrappers ensures that data is secure. A system of feedback loops ensures that information travels through the system quickly and effectively.
\end{abstract}

\section{Introduction}

The emphasis of intelligent networks in mobile computing has been based on flexible architectures capable of controlling the switches that perform the connectivity depending on service [1]. This means that intelligence is mainly related to the support for rapid and low cost deployment of new services. However, there is a new interest in the power of customisation for advanced and multimedia services [2]. In this case, users are not only interested in a variety of packaged services but also in those services that introduce options and functional features that the user can select. The challenge in providing these services is that the changes can happen at run time, as well as only during deployment. Furthermore, reconfigurable networks require sophisticated information gathering and processing capabilities. The intelligent layers of the system need to provide structures and algorithms to intelligently manage resources within the base station as users enter/leave the coverage area. Reconfiguration may occur as part of long term planning, real time or live. The intelligent system must decide which to invoke and when using suitable prioritising strategies.
A more challenging situation occurs when the network itself can take decisions on behalf of the user [3]. In this case, although intelligent agent technology has become key in providing intelligent personal support for users [4], the expectations have been higher than the real results that current agent technology can offer. A key issue is that, in order to offer the best advice and manage complex resources effectively, the intelligent system requires access to large amounts of information viewed from multidimensional perspectives, and intelligent agents are not usually designed to deal with such a large amount of data. Further support can be provided by data mining, using 'a process of exploration and analysis... in order to discover meaningful patterns and rules' [4], allowing the system to correlate data from many users in different situations to provide global solutions. This provides the bigger picture needed in monitoring and controlling large mobile networks while agent technology provides the individual support.

Since data mining [5] only works if large amounts of data have been collected and structured, data mining in this context needs to be combined with a data warehousing architecture. The data warehouse supports a creation of a single logical view from different sources [6]. For example, to monitor and control resources effectively, it is important to combine historical data of network usage with current trends, availability data, costs of services and access times. The data warehouse helps derive future forecasts and analyses trends without interfering in the operation of the network unless it is warranted.

The intelligent software is added as part of a new architectural model that can combine the above technologies. The architecture, CODA (Complex Organic Distributed Architecture), combines data warehousing, data mining and agent technology [7] as shown in Figure 1. Intelligent support is based on the way organic systems manage complex and adaptive behaviour. The CODA system refines and adapts Beers Viable Systems Model [8] 


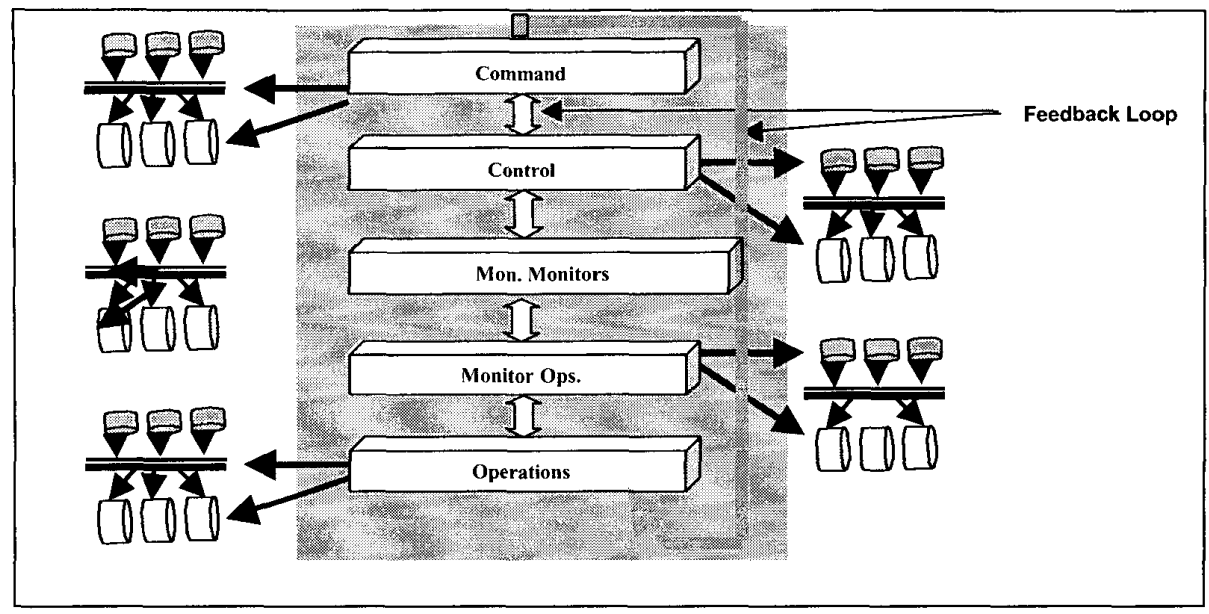

Figure 1: The General Structure of CODA

Incoming data is levelled according to the type of activity performed and filtered so that only the relevant information is presented when decisions are made [7]. The CODA model divides layers into the five "necessary and sufficient' subsystems involved in any viable organism and organisation [8]. However, the intelligent reconfiguration system can be implemented as the four lower layers only [9], as shown in Figure 2.



Figure 2: CODA Component Layers 
Component Layer Descriptions

1. Operational Layer: This deals with the typical transactions and operations of the system. Transactions are semi autonomous and operate independently of the intelligent system unless preset operational critical success factors are exceeded (in which case the relevant intelligent software is alerted), or if agent software can perceive a need for modification.

2. Monitor Operations Layer: The data is aggregated and dimensions are added if required. Simple OLAP (On Line Analytical Processing) techniques [6] are applied. Useful aggregations include the network usage at the time of day; useful dimensions include placing users into distinct user groups. This allows reconfiguration to be managed effectively.

3. Monitor the Monitors Layer: This deals with multidimensional data and provides capability for analysing trend behaviour [6]. The system at this level is monitored in terms of external trends so data from external source databases is added. More powerful OLAP techniques can be applied. For example, it is possible to make predictions for network usage at different times of the day by different groups of users.

4. Control Layer: This layer allows the system to leam about simple emergent behaviour based on trends identified by the layer below. Note that the system is untrammelled by unnecessary data, but, with permissions, may 'drill down' to the data bate layers below, and interrupt operations if threats or opportunities are perceived. For example, it is possible to compare predicted behaviour (using the forecast data dimension) with actual behaviour (using the version data dimension) and make adjustments (up to the number of dimensions determined by the accuracy needs of the system).

\section{Intelligent Support}

The CODA system treats the MS, BS, BSC and MSC as components drawn as classes [1213]. These classes are characterised by the fact that they consist of wrappers and filters. The CODA system wrappers and filters do not require changes to existing systems since they are held in software. These CODA components wrap several sub classes and objects. Communication between classes is via tasks (using a core task interaction language which is currently in development). The wrapper class structure is shown in Figure 3.

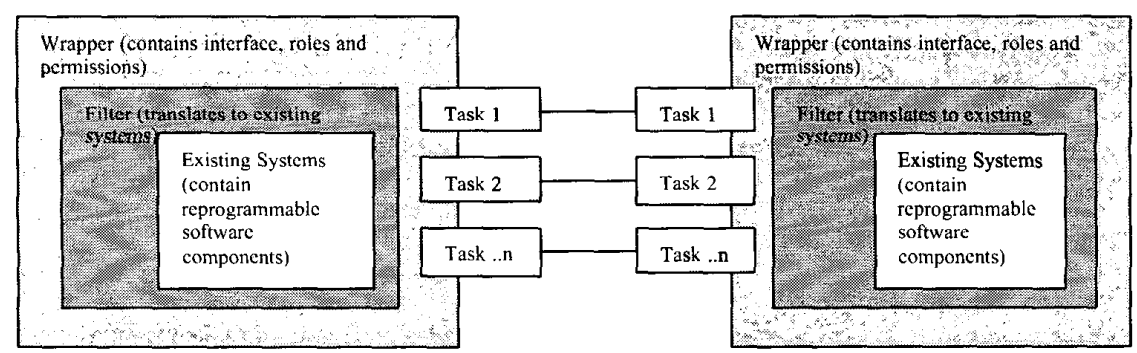

Figure 3: The Wrapper Class Structure

There are two types of wrapper class, agents and resources. Agents are able to request reconfiguration amendments using rules as well as activate tasks and request actions from agents. Resource classes cannot request reconfiguration.
Figure 4 describes MS, BS BSC and MSC interactions. CODA does not add new functionality unless the system requires it. CODA initially ensures that existing objectives are met and then adapts as more information becomes available. 


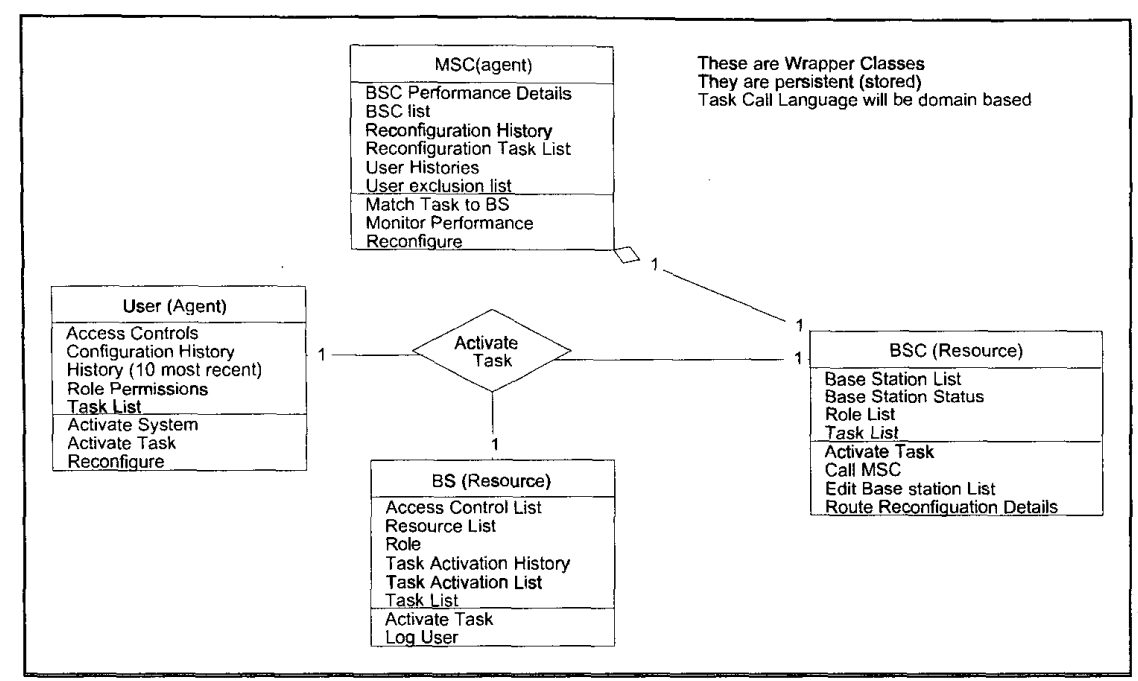

Figure 4: Classes in the Operational and Monitoring Layers

The CODA system is an organic model. Intelligence in the system is based on adaptive behaviours. In order to adapt, the system must match current information with information in memory. Trends are discovered using data mining techniques and new objectives, threats and opportunities are discovered on the basis of analysis of the data. The classes shown below are persistent (i.e. all data, events and actions are stored in the databases described in diagram 2).

MS class data is stored in both the operational and in the monitoring layer (although the monitoring layer holds of the most recent tasks only). The MS contains programmable memory, and can store the past configuration (configuration history), and the past ten tasks executed. It can also store the role details including user status, role and task permissions. A more complete user history is held in the monitoring layer. Security is managed using Role Based Access Controls [10].

\section{Conclusions}

A technique for the intelligent evolution of mobile systems using a Complex Organic Distributed Architecture (CODA) was described, which supports intelligent reconfiguration of all system components. On Line Analytical Processing (OLAP) software is used to monitor and control data in the system. An effective system of filters and wrappers and feedback loops ensures that information can travel through the system quickly and effectively. This technique has applications in software radio systems for forth generation mobile communications.

\section{Acknowledgement}

This document is based on work carried out in the EU-sponsored collaborative research project CAST

(http://www.cast5.freeserve.co.ulk).

Nevertheless, only the authors are responsible for the views expressed here.

\section{References}

[1] H. Zuidweg M. Campolargo, J. Delgado and A. Mullery Eds. Intelligence in Services and Networks, $6^{\text {th }}$ International Conference on Intelligence and Services in Networks. LNCS 1597, Springer, 1999 [2] L. Maknavicius, G. Koscielny and S. Znaty: Customising Telecommunications Services: Patterns, Issues and Models in [1]

[3] E. Kaasienen: Usability Challenges in Agentbased Services in [2]

[4] G. Weiss: Multiagent Systems: A Moderm Approach to Distributed Artificial Intelligence, MIT Press 1999.

[5] M. J. A. Berry and G. S. Linoff: Mastering Data Mining, Wiley, 2000.

[6] H. Singh: Data Warehousing - Concepts, Technologies, Implementations and Management, Prentice-Hall, 1998. 
[7] T. Karran, G.R. Justo, M. J. Zemerly An Organic Architecture for component Evolution in Decisions Systems, SCI2000 Conference Proceedings July 2000

[8] R. Espejo, R. Schuhmann, W. and $M$. Schwaninger, Organisational Transformation and Learning, A Cybernetic Approach to Management Wiley, 1996

[9] G. Justo, T. Karran Proposed Architecture for CODA/CAST. Technical Paper University of Westminster 2000

[10] S. Megaache, T. Karran, G. R. Ribeiro Justo. A Role-based Security Architecture for Business Intelligence. Conference Proceedings Tools 2000 July 2000

[11] R. Ribeiro Justo, G. R. and P. Cunha. An Architectural Application Framework for Evolving Distributed Systenss. Journal of Systems Architecture: Special Issue on New Trends in Programming and Execution Models for Paralle Architectures, Heterogeneous Distributed Systems and Mobile Computing, Vol. 45:1375-1384, 1999.

[12] K. Madani et al, "Configurable Radio with Advanced Software Technology (CAST) - Initial Concepts", Proc. IST Mobile Summit 2000, Galway - Ireland, pp 139-144, 1-4 October 2000.

[13] R.E. Ramos, K. Madani, "A novel Generic Distributed Intelligent Re-Configurable Mobile Network Architecture", accepted for presentation at the VTC - spring, Rhodes - Greece, May 6-9 2001 . 